\author{
О. А. Севко
}

Белорусский государственный технологический университет

\title{
ВЛИЯНИЕ ИЗМЕНЕНИЯ ПРОСТРАНСТВЕННОЙ СТРУКТУРЫ НА ПРИРОСТ ВТОРОГО ЯРУСА ЕЛИ В СЛОЖНОМ ДРЕВОСТОЕ
}

В работе представлено исследование влияния изменения пространственной структуры на прирост еловой части сложного древостоя и возможности формирования оптимальной пространственной структуры рубками ухода. Полученные результаты позволяют оптимизировать проводимые рубки ухода для увеличения прироста древостоев и получения максимальной прибыли от лесовыращивания.

На основании пространственного распределения деревьев в сложном древостое проводилась оценка их межвидового влияния на рассматриваемые деревья ели, находящиеся во втором ярусе. При исследовании использовался регрессионный анализ зависимости радиального прироста от пространственной структуры древостоя вокруг исследуемых деревьев. Радиальный прирост изучался по всем кернам, взятым у 20\% деревьев ели на пробной площади. Оценено влияние соседних деревьев на центральные деревья и выявлены наиболее значимые воздействующие параметры.

Установлено, что увеличение прироста по объему через 5-6 лет после рубки ухода достигало 3037\%. Коэффициенты корреляции рассматриваемых уравнений связи таксационных показателей исследуемых деревьев ели от пространственной структуры древостоя достигали 0,67-0,72. Наибольшее влияние при этом оказывали деревья сосны и березы, находящиеся в первом ярусе древостоя.

Ключевые слова: текущий прирост, пространственная структура, сосново-березовый древостой, регрессионный анализ.

Для цитирования: Севко О. А. Влияние изменения пространственной структуры на прирост второго яруса ели в сложном древостое // Труды БГТУ. Сер. 1, Лесное хоз-во, природопользование и перераб. возобнобляемых ресурсов, 2021. № 2 (246). С. 28-35.

\section{O. A. Sevko}

Belarusian State Technological University

\section{THE INFLUENCE OF CHANGES IN THE SPATIAL STRUCTURE ON THE GROWTH OF THE SECOND LAYER OF SPRUCE IN A COMPLEX TREE}

The paper presents a study of the influence of changes in the spatial structure on the growth of the spruce part of a complex stand and the possibility of forming an optimal spatial structure by thinning. The results obtained make it possible to optimize the ongoing thinning to maximize the growth of forest stands and to maximize the profit from forest growing.

Based on the spatial distribution of trees in a complex forest stand, an assessment was made of the interspecific influence of trees on the considered spruce trees located in the second tier of the stand. The study used a regression analysis of the dependence of radial growth on the spatial structure of the stand around the trees under study. Radial growth was studied using core samples taken from $20 \%$ of spruce trees on the test plot. The influence of neighboring trees on the central trees was assessed and the most significant influencing parameters were determined.

It was revealed that the increase in volume gain 5-6 years after thinning reached 30-37\%. The correlation coefficients of the considered equations of the relationship between the taxation indicators of the studied spruce trees from the spatial structure of the stand reached $0.67-0.72$. The greatest influence is exerted by pine and birch trees, located in the first tier of the stand.

Key words: current growth, spatial structure, current growth, spatial structure, pine-spruce forest stand, regression analysis.

For citation: Sevko O. A. The influence of changes in the spatial structure on the growth of the second layer of spruce in a complex tree. Proceedings of BSTU, issue 1, Forestry. Nature Management. Processing of Renewable Resources, 2021, no. 2 (246), pp. 28-35 (In Russian).

Введение. Механизм формирования деревьев того или иного вида в лесу протекает под воздействием соседей, которые оказывают друг на друга взаимное влияние, изменяя ве- личину и форму кроны, высоту и форму стволов. При этом следует учитывать освещение, защиту от ветра и другие экологические факторы $[1,2]$. 
Исследования динамики таксационных показателей смешанных древостоев приведены в различных литературных источниках как белорусских, так и зарубежных авторов $[3,4]$.

Естественное возобновления ели под пологом приспевающих и спелых насаждений было проанализировано в трудах К. В. Лабохи и Д. В. Шимана [5]. Исследования показали, что более успешное естественное возобновление ели наблюдается в подзоне грабово-дубовотемнохвойных лесов и дубово-темнохвойных лесов, в которых обеспечение подростом спелых и приспевающих насаждений ели составляет 47,7 и $45,5 \%$.

Условия, которые делают возможным наличие общественной жизни древесных растений, характеризуются прежде всего дифференцированием деревьев по классам доминирования. Потребность растений увеличивать площадь своей деятельности путем роста - неотъемлемая способность их к завоеванию пространства.

Развитие подпологовой ели в березняках черничных рассмотрено в работах В. Н. Коновалова и В. Л. Зарубиной [6]. Максимальная интенсивность роста у ели прослеживается в 8-летнем березняке. При увеличении возраста березы у подпологовой ели наблюдается дефицит солнечной энергии, что приводит к снижению ростовых процессов. Самый низкий показатель роста и развития ели отмечен в момент достижения березой возраста спелости. Для сохранения высокой жизнедеятельности ели в березняках необходимо своевременно осуществлять меры содействия путем проведения рубок ухода.

Эти же авторы выполнили исследование изменения биологических особенностей ели в березняках после проведения выборочных рубок. Выборочные рубки в березняках улучшают условия роста, а также фотосинтез подроста. Наиболее благоприятные условия для роста елового подроста в лиственных насаждениях складываются при полноте 0,5 [7].

Естественное и искусственное возобновление ели, только уже на площадях лесных культур, исследовалось в работах А. Г. Шахова, А. В. Грязькина и В. 3. Нгуен [8]. Авторы сделали вывод, что молодое поколение естественного происхождения жизнеспособнее. В целом состояние самосева и культур ели намного лучше, чем сосны (как искусственного, так и естественного происхождения).

Исследование Д. Н. Торбик показало зависимость густоты подроста от месторасположения по отношению к волоку [9]. Для подроста ели связь между расстоянием от волока и густотой очень высокая. Также был выполнен анализ влияния рубок на таксационные показатели древостоя. Наблюдалось увеличение сред- него диаметра и запаса древостоя на участках пасек, расположенных вдоль волоков (средний диаметр на 0,5-1,0 см, а запас на $15-25 \mathrm{~m}^{3} /$ га больше соответствующих показателей древостоя центральных частей пасек). С увеличением времени, прошедшего с момента рубки, различия таксационных характеристик древостоя на крайних и центральных участках пасек увеличиваются.

Как правило, конкурентные отношения и их влияние на характеристики древостоев могут оцениваться: а) без учета характеристик центрального дерева, но с выявлением оптимального радиуса влияния; б) с учетом характеристик центрального дерева, но без выявления оптимального радиуса влияния.

Однако В. А. Усольцев и М. М. Семышев совмещают различные подходы и определяют влияние нескольких показателей конкуренции на фитомассу и прирост ствола дерева с учетом его таксационных характеристик и с установлением оптимального радиуса влияния в чистых естественных и искусственных сосняках [10].

Влияние конкурентных отношений, связанных с размещением деревьев по площади, на биопродуктивность деревьев рассматривалось в работах С. Н. Сеннова [11]. Вклад конкуренции, или количественное выражение конкурентных отношений, предлагается определять с использованием индекса конкуренции (CI). Аналогичный подход прослеживается в работах В. В. Коцана $[12,13,14]$ и О. А. Севко [15].

Основная часть. Для выявления влияния изменения пространственной структуры на прирост ели была заложена пробная площадь в сложном 65-летнем сосново-березовом древостое со вторым ярусом ели.

На пробной площади выполнялась подеревная таксация с проведением картирования расположения всех деревьев. Для каждого дерева методом линейных засечек с помощью ультразвукового дальномера определялись местоположение в системе условных координат, по два перпендикулярных диаметра, высота дерева, высота начала кроны, 4 радиуса кроны.

С помощью компонентов геоинформационной системы Quantum-GIS была сформирована цифровая карта пробной площади (рис. 1) с векторным и атрибутивным слоями.

Для выявления регрессионных уравнений связи показателей радиального прироста методом стратифицированной выборки было отобрано 28 стволов ели (что составило $20 \%$ от количества деревьев ели), у которых брались керны. Далее для каждого из выбранных центральных деревьев ели были определены деревья-соседи на расстоянии, равном радиусам 
крон деревьев-соседей. Оценивалось также и влияние изменения пространственной структуры: влияние расстояния до пней, появившихся в результате рубки ухода (рис. 2).

Собранные керны сканировались и обрабатывались также с помощью Quantum-GIS: определялись размеры десяти последних годичных слоев (рис. 3).
Для оценки влияния пространственной структуры на таксационные показатели деревьев второго яруса ели сначала проводился регрессионный анализ влияния растущих деревьев-соседей на центральные деревья. В качестве зависимых показателей использовались диаметр $(D)$, высота $(H)$, радиус кроны $(K)$ и радиальный прирост $\left(Z_{r}\right)$ центральных деревьев.

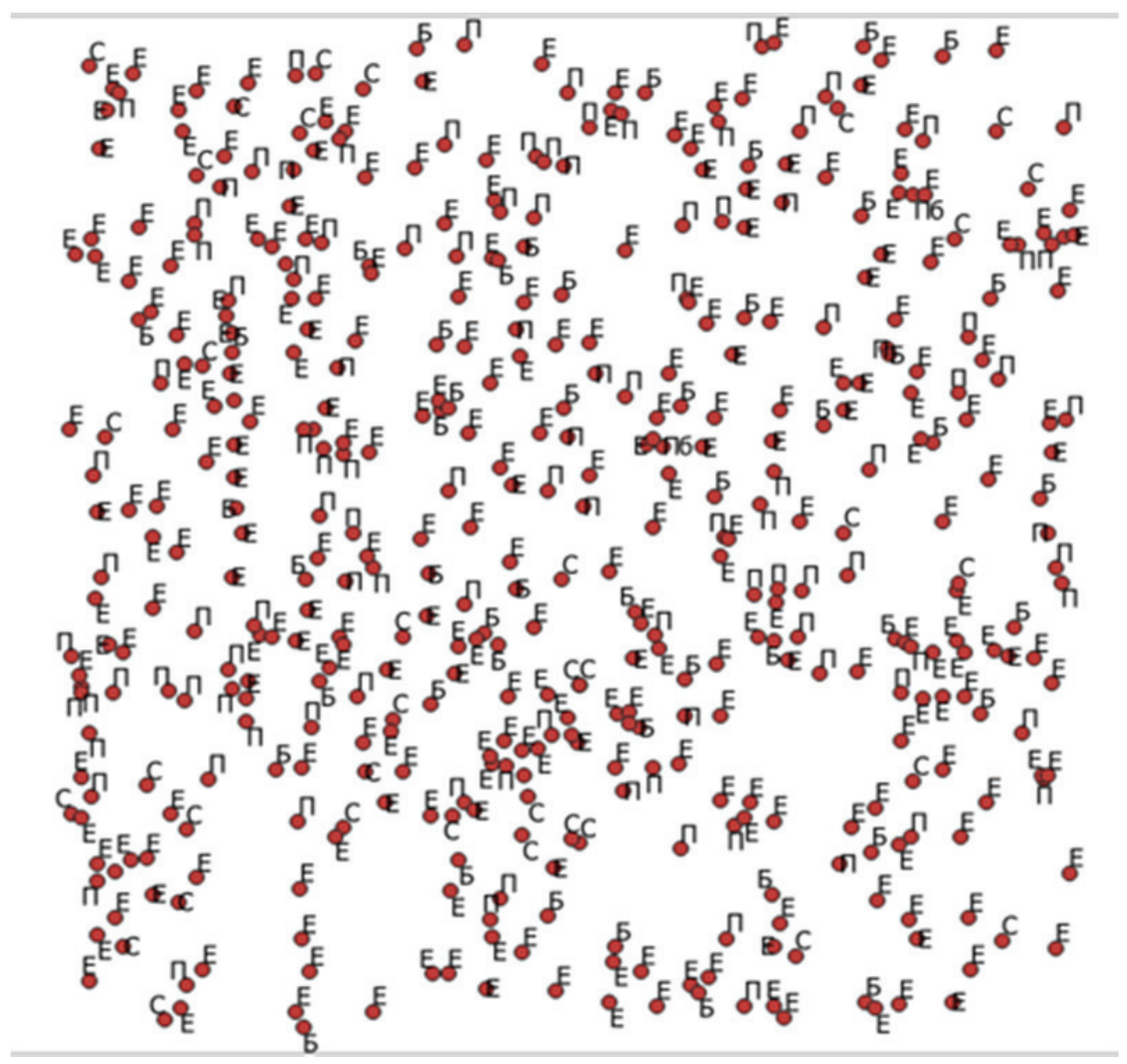

Рис. 1. Расположение деревьев на пробной площади

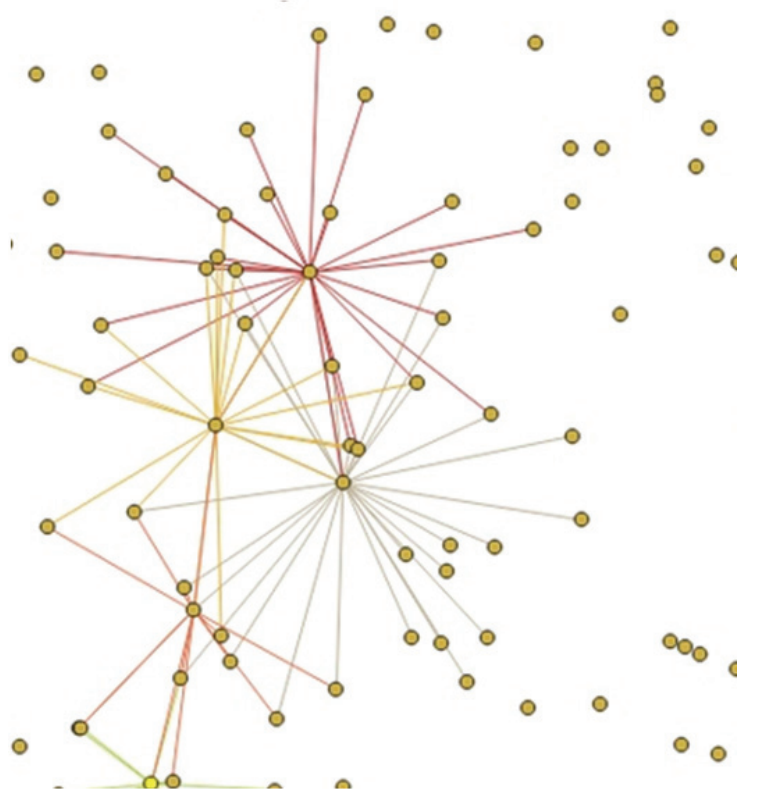

Рис. 2. Расположение деревьев-соседей

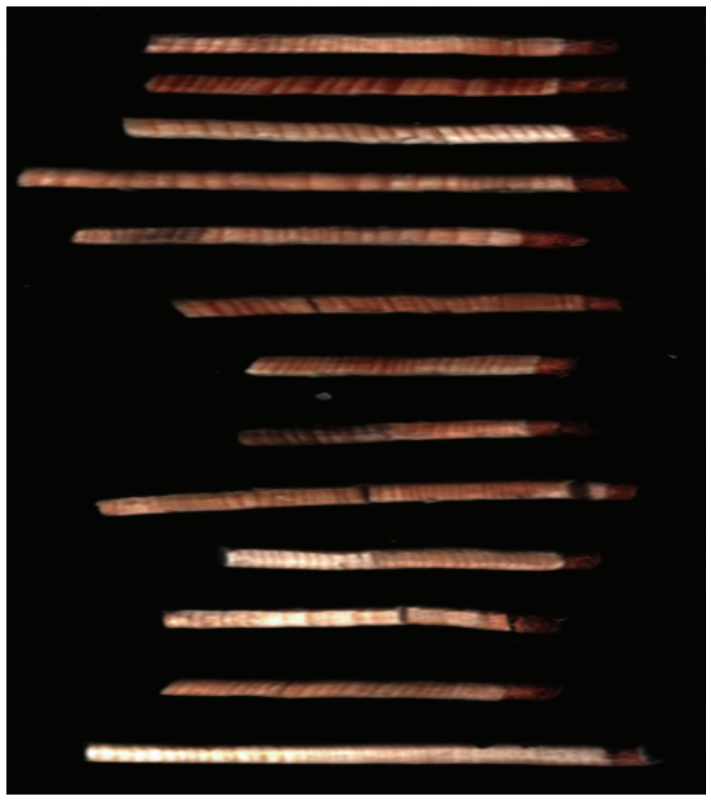

Рис. 3. Подготовленные к измерениям отсканированные керны в Quantum-GIS 
В уравнениях связи учитывались средний радиус кроны деревьев-соседей, их средняя высота и средний диаметр, а также среднее расстояние между деревьями $(L)$. Для деревьевсоседей каждой породы составлялись отдельные регрессионные уравнения.

Результаты регрессионного анализа показали практически отсутствие влияния деревьев второго яруса ели на таксационные показатели аналогичных центральных деревьев ели (коэффициент корреляции $(R)$ от 0,33 до 0,47$)$. Это объясняется достаточно большим расстоянием между данными деревьями и визуально большим влиянием первого яруса древостоя.

Гораздо теснее зависимость тех же таксационных характеристик с параметрами деревьевсоседей сосновой части, находящихся уже в первом ярусе ( $R$ от 0,48 до 0,72$)$. Крупные кроны сосны, затеняющие деревья второго яруса, в полной мере объясняют данную корреляцию.

Достаточно весомое влияние деревьев-соседей березовой части древостоя ( $R$ от 0,41 до $0,63)$, что также объясняется нахождением березы в первом ярусе. Однако их количество го- раздо меньше, расстояние гораздо больше, соответственно меньшее влияние на таксационные показатели центральных деревьев ели оказывается (табл. 1).

Далее оценивалась зависимость таксационных показателей центральных деревьев ели от находящихся рядом пней, которые образовались в результате рубки 6 лет назад. Если использовать в уравнениях таксационные показатели на данный момент и средний за 10 лет радиальный прирост, то значительной корреляции не наблюдается ( $R$ от 0,43 до 0,46$)$ (табл. 2).

Для получения уточненных данных радиальный прирост изучался по годам за последние 10 лет. В результате было выявлено, что после рубки близстоящих деревьев прирост значительно увеличился.

Это доказывают проценты увеличения прироста по диаметру $(\sim 50 \%)$ и объему ( 30\%): после рубки с каждым годом идет постепенное увеличение прироста (табл. 3). Максимальный радиальный прирост составил 4,71 мм, минимальный - 0,24 мм (рис. 4).

Таблица 1

Регрессионные уравнения связи показателей ели от параметров деревьев-соседей

\begin{tabular}{|c|c|c|}
\hline $\begin{array}{l}\text { Деревья- } \\
\text { соседи }\end{array}$ & Уравнения & $\begin{array}{l}\text { Коэффициент } \\
\text { корреляции } R\end{array}$ \\
\hline \multicolumn{3}{|c|}{ Радиальный прирост $Z_{r}$} \\
\hline Ель & $b_{0}+b_{1} \cdot\left(L^{3}+K\right)+b_{2} / H_{1}+b_{3} / D^{3}$ & 0,33 \\
\hline Сосна & $b_{0}+b_{1} / L+b_{2} \cdot H^{2}+b_{3} \cdot D^{2}$ & 0,72 \\
\hline Береза & $b_{0}+b_{1} / L+b_{2} \cdot H^{3}+b_{3} \cdot D^{2}$ & 0,51 \\
\hline \multicolumn{3}{|c|}{ Диаметр $D$} \\
\hline Ель & $b_{0}+b_{1} \cdot\left(L+K^{3}\right)+b_{2} \cdot H+b_{3} / D^{2}$ & 0,40 \\
\hline Сосна & $b_{0}+b_{1} / L^{3}+b_{2} \cdot H^{2}+b_{3} / D^{3}+b_{4} / K$ & 0,48 \\
\hline Береза & $b_{0}+b_{1} / L+b_{2} \cdot H^{2}+b^{3} \cdot D^{3}$ & 0,47 \\
\hline \multicolumn{3}{|c|}{ Высота $H$} \\
\hline Ель & $b_{0}+b_{1} \cdot\left(L+K^{3}\right)+b_{2} \cdot H_{1}^{3}+b_{3} / D_{1}^{2}$ & 0,35 \\
\hline Сосна & $b_{0}+b_{1} / L^{3}+b_{2} \cdot H^{3}+b_{3} / D^{3}+b_{4} / K$ & 0,57 \\
\hline Береза & $b_{0}+b_{1} / L+b_{2} \cdot H_{2}+b^{3} \cdot D^{3}$ & 0,47 \\
\hline \multicolumn{3}{|c|}{ Радиус кроны $K$} \\
\hline Ель & $b_{0}+b_{1} \cdot\left(L+K^{3}\right)+b_{2} \cdot H^{3}+b_{3} / D^{2}$ & 0,47 \\
\hline Сосна & $b_{0}+b_{1} / L^{3}+b_{2} \cdot H^{2}+b_{3} / D^{3}+b_{4} / K^{3}$ & 0,67 \\
\hline Береза & $b_{0}+b_{1} /(L \cdot K)+b_{2} / H^{2}+b_{3} / D^{3}$ & 0,63 \\
\hline
\end{tabular}

Регрессионные уравнения связи показателей ели от расстояния до пней

Таблица 2

\begin{tabular}{|l|c|c|}
\hline \multicolumn{1}{|c|}{ Показатель } & Уравнения & Коэффициент корреляции $R$ \\
\hline$Z_{r}$ & $b_{0}+b_{1} \cdot L+b_{2} \cdot L^{3}$ & 0,46 \\
\hline$D$ & $b_{0}+b_{1} / L+b_{2} \cdot L^{3}$ & 0,43 \\
\hline$H$ & $b^{0}+b^{1} / L+b^{2} \cdot L^{3}$ & 0,46 \\
\hline
\end{tabular}


Таблица 3

Показатели радиального прироста центральных деревьев ели

\begin{tabular}{|l|c|c|c|c|c|c|c|c|}
\hline \multirow{2}{*}{$\begin{array}{c}\text { Номер } \\
\text { годичного слоя }\end{array}$} & \multicolumn{7}{|c|}{ Номер дерева } \\
\cline { 2 - 10 } & 17 & 246 & 318 & 138 & 242 & 236 & 15 & 324 \\
\hline 1 & 0,40 & 0,55 & 1,62 & 0,89 & 0,79 & 0,24 & 0,37 & 1,34 \\
\hline 2 & 0,24 & 0,73 & 1,22 & 0,74 & 0,99 & 0,34 & 0,50 & 1,27 \\
\hline 3 & 0,34 & 1,42 & 1,14 & 0,60 & 0,99 & 0,36 & 0,55 & 1,17 \\
\hline 4 & 0,53 & 1,32 & 1,12 & 0,62 & 1,29 & 0,73 & 0,41 & 0,92 \\
\hline 5 & 0,99 & 1,74 & 0,97 & 0,77 & 0,97 & 0,92 & 0,46 & 1,10 \\
\hline 6 & 0,60 & 1,81 & 1,44 & 0,87 & 1,54 & 1,19 & 0,75 & 1,22 \\
\hline 7 & 0,84 & 1,41 & 2,83 & 1,54 & 1,22 & 1,18 & 0,58 & 2,55 \\
\hline 8 & 1,14 & 2,26 & 2,63 & 1,74 & - & 0,91 & 0,73 & 2,31 \\
\hline 9 & 1,17 & 1,49 & 3,03 & 1,34 & - & 1,17 & 0,78 & 2,73 \\
\hline 10 & 1,04 & 1,39 & 4,71 & 1,49 & - & 1,60 & 1,41 & 1,78 \\
\hline $\begin{array}{l}\text { Средний прирост до } \\
\text { рубки, мм }\end{array}$ & 0,38 & 1,00 & 1,21 & 0,71 & 0,93 & 0,31 & 0,46 & 1,16 \\
\hline $\begin{array}{l}\text { Средний прирост } \\
\text { после рубки, мм }\end{array}$ & 0,96 & 1,68 & 2,93 & 1,29 & 1,24 & 1,10 & 0,85 & 2,12 \\
\hline $\begin{array}{l}\text { Увеличение приро- } \\
\text { ста, \% }\end{array}$ & 60,65 & 40,43 & 58,59 & 44,66 & 25,33 & 71,77 & 45,94 & 45,21 \\
\hline
\end{tabular}

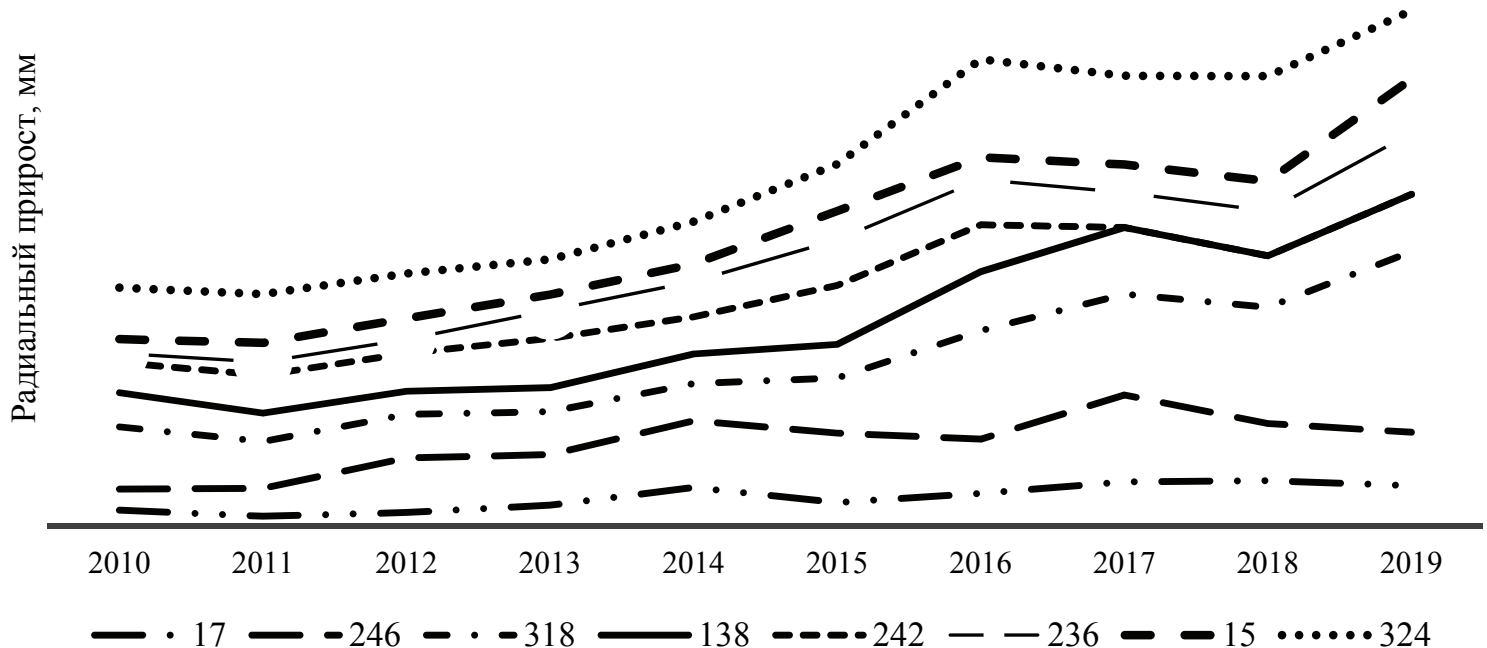

Рис. 4. Изменение радиального прироста

Далее на основании ширины годичного слоя рассчитывался прирост дерева по объему. Процент текущего прироста по объему определялся по формуле (способ Шнейдера):

$$
P_{V}=\frac{K \cdot i}{D},
$$

где $K$ - коэффициент, зависящий от протяженности кроны и энергии роста в высоту;

$i$ - ширина годичного слоя, мм;

$D$ - диаметр без коры на высоте 1,3 м в настоящее время, см.

На основании процента прироста по объему находился абсолютный прирост по объему. Исследование показало, что прирост по объему после рубки увеличился примерно на 8-30\%, что является очень большим показателем влияния (табл. 4).

Различия между приростами деревьев, находившихся под влиянием до рубки, и деревьев, не подверженных влиянию срубленных, оказались также значительными. У деревьев, находившихся под влиянием, после проведения рубки средний радиальный прирост увеличился по сравнению с приростом деревьев без влияния на $30-50 \%$ (рис. 5 ).

Исследование подтвердило влияние пространственной структуры древостоя и ее изменений на таксационные показатели деревьев ели, находящихся во втором ярусе сложно сосново-березового древостоя. 
Таблица 4

Оценка увеличения прироста по объему центральных деревьев ели

\begin{tabular}{|c|c|c|c|c|c|c|}
\hline № & $\begin{array}{c}\text { Номер } \\
\text { дерева } \\
\text { на ПП }\end{array}$ & $\begin{array}{c}\text { Прирост } \\
\text { по объему } \\
\text { до рубки, } \text { 3 }^{3}\end{array}$ & $\begin{array}{c}\text { Прирост } \\
\text { по объему } \\
\text { после рубки, } \mathbf{M}^{3}\end{array}$ & $\begin{array}{c}\text { Процент прироста } \\
\text { по объему } \\
\text { до рубки, \% }\end{array}$ & $\begin{array}{c}\text { Процент прироста } \\
\text { по объему } \\
\text { после рубки, \% }\end{array}$ & $\begin{array}{c}\text { Процент } \\
\text { увеличения } \\
\text { прироста } \\
\text { по объему,\% }\end{array}$ \\
\hline 1 & 17 & 0,01 & 0,04 & 18,51 & 46,77 & 28,26 \\
\hline 2 & 246 & 0,10 & 0,16 & 24,09 & 40,47 & 16,38 \\
\hline 3 & 318 & 0,13 & 0,32 & 26,28 & 63,64 & 37,36 \\
\hline 4 & 138 & 0,04 & 0,07 & 28,30 & 51,42 & 23,12 \\
\hline 5 & 242 & 0,08 & 0,11 & 26,24 & 34,99 & 8,75 \\
\hline 6 & 236 & 0,02 & 0,06 & 11,63 & 41,25 & 29,63 \\
\hline 7 & 15 & 0,02 & 0,03 & 18,61 & 34,39 & 15,78 \\
\hline 8 & 324 & 0,09 & 0,16 & 37,15 & 67,89 & 30,74 \\
\hline
\end{tabular}

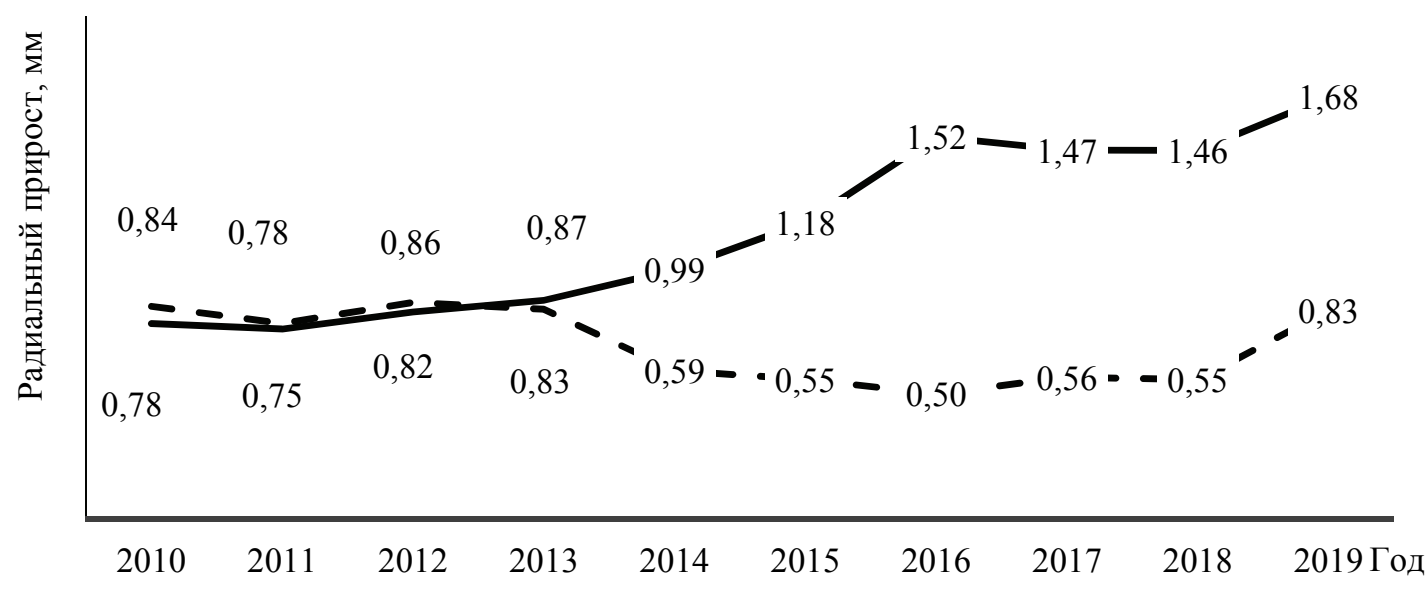

\section{—— Прирост деревьев, находившихся под влиянием \\ - - Прирост деревьев без влияния}

Рис. 5. Изменения радиального прироста после рубки

Заключение. Анализируя данные влияния показателей деревьев-соседей на таксационные показатели центральных деревьев ели, можно сделать вывод, что находящиеся во втором ярусе деревья ели оказывают слабое воздействие друг на друга. Значительно большая зависимость прослеживается от деревьев пород, произрастающих в первом ярусе. При этом весомое влияние оказывается на показатели радиального прироста и радиуса кроны. В результате проведенных исследований можно сделать вывод, что в сложном насаждении на второй ярус ели в большей степени воздействует влияние межвидовая конкуренция, чем внутривидовая.

Оценка влияния изменения пространственной структуры, а именно расстояния до вырубленных стволов (пней), показала, что корреляция таксационных показателей деревьев ели на настоящий момент и расстояний до пней невысокая. Но при детальном рассмотрении воздействия срубленных деревьев на близстоящие мы видим, что изменения радиального прироста и прироста по объему имеют очень большие показатели (30-50\%). Даже коэффициент корреляции со средними расстояниями до пней составил 0,46 .

Следовательно, оптимизация рубок ухода и возможность выявления оптимального расстояния между остающимися после рубок деревьями позволит максимизировать прирост древостоев.

Изучение влияния изменения пространственной структуры параллельно с оценкой межвидовых отношений в древостое позволяет выявить основные направления для дальнейшего изучения и правильно организовать постановку эксперимента в будущем по вопросу воздействия пространственной структуры на развитие смешанных и сложных древостоев. 


\section{Список литературы}

1. Морозов Г. Ф. Учение о лесе. М.: Госиздательство сельскохозяйственной литературы. $1931.456 \mathrm{c}$.

2. Балакир М. В. Распределение диаметров деревьев в еловых древостоях искусственного происхождения // Труды БГТУ. 2012. № 1: Лесное хоз-во. С. 30-32.

3. Взаимоотношения древесных пород в чистых и смешанных насаждениях / И. Н. Рахтеенко [и др.] // Эколого-физиологические основы взаимодействия растений в фитоценозах. 1976. $116 \mathrm{c}$.

4. Грибанов В. Я. Пространственная структура сосновых и лиственных деревьев // Продуктивность лесных фитоценозов. 1984. С. 42-47.

5. Лабоха К. В., Шиман Д. В. Особенности естественного возобновления под пологом приспевающих и спелых еловых насаждений на почвах недостаточного и умеренного увлажнения // Труды БГТУ. 2010. № 1: Лесное хоз-во. С. 72-75.

6. Коновалов В. Н., Зарубина Л. В. Оценка жизнеспособности ели в березняке черничном в процессе его возрастного развития // Известия высших учебных заведений. Лесной журнал. 2016. № 5 (353). C. $44-60$.

7. Зарубина Л. В. Рост подпологового возобновления ели на вырубках березняка черничного // Известия Санкт-Петербургской лесотехнической академии. 2016. № 216. С. 58-68.

8. Шахов А. Г., Грязькин А. В., Нгуен В. 3. Самовозобновление ели на площадях лесных культур // Международный научный журнал «Символ науки». № 4/2016. URL: https:/cyberleninka.ru /article/n/ samovozobnovlenie-eli-na-ploschadyah-lesnyh-kultur (дата обращения: 11.03.2021).

9. Торбик Д. Н. Изменение экологических факторов в связи с рубками хода и их влияние на формирование насаждений. Архангельск: Поморский государственный университет имени М. В. Ломоносова, 2010. 20 с.

10. Усольцев В. А., Семышев М. М. Продукционные характеристики с учетом конкуренции деревьев в искусственных и естественных сосняках: сравнительный анализ. Екатеринбург: УрОРАН, 2007. $137 \mathrm{c}$.

11. Сеннов С. Н. Итоги экспериментального изучения конкуренции в древостоях // Известия С.-Петербургской лесотехнической академии. 1993. 172 с.

12. Коцан В. В. Взаимосвязи между таксационными показателями деревьев в кругах конкуренции на примере сосняков мшистых искусственного происхождения // Труды БГТУ. 2014. № 1: Лесное хоз-во. С. 19-22.

13. Коцан В. В. Классификация деревьев на основании пространственной структуры при назначении в рубки ухода // Труды БГТУ. 2015. № 1: Лесное хоз-во. С. 24-27.

14. Коцан В. В. Оценка влияния пространственной структуры на таксационные показатели древостоев с использованием цифровой модели пространственного распределения // Лесное хозяйство: тезисы докладов 76-й науч.-техн. конф. профессорско-преподавательского состава, научных сотрудников и аспирантов, Минск, 13-20 февр. 2012 г. / Белорус. гос. технол. ун-т; редкол.: О. А. Атрощенко (гл. ред.) [и др.]. Минск, 2012. С. 13.

15. Севко О. А. Оценка зависимости текущего прироста сосновой части смешанных сосновоберезовых древостоев от их пространственной структуры // Труды БГТУ. 2015. № 1: Лесное хоз-во. C. $41-45$.

\section{References}

1. Morozov G. F. Ucheniye o lese [The doctrine of the forest]. Moscow, Gosizdatel'stvo sel'skokhozyaystvennoy literatury Publ., 1931. 456 p.

2. Balakir M. V. Distribution of tree diameters in spruce stands of artificial origin. Trudy BGTU [Proceedings of BSTU], 2012, no. 1, Forestry, pp. 30-32 (In Russian).

3. Rakhteenko I. N., Martinovich B. S., Krot L. A. The relationship of tree species in clean and mixed stands. Ekologo-fiziologicheckiye osnovy vzaimodeystviya rasteniy $v$ fitotsenozakh [Ecological and Physiological Basis for the Interaction of Plants in Phytocenoses], 1976. 116 p. (In Russian).

4. Gribanov V. Ya. The spatial structure of pine and deciduous trees. Produktivnost' lesnykh fitotsenozov [Productivity of forest phytocenoses], 1984, pp. 42-47 (In Russian).

5. Labokha K. V., Shiman D. V. Features of natural regeneration under the canopy of ripening and ripe spruce plantations on soils of insufficient and moderate moisture. Trudy BGTU [Proceedings of BSTU], 2010, no. 1, Forestry, pp. 72-75 (In Russian). 
6. Konovalov V. N., Zarubina L. V. Evaluation of the viability of spruce in a blueberry birch forest in the process of its age development. Izvestiya vysshikh uchebnykh zavedeniy. Lesnoy zhurnal [News of higher educational Institutions. Forest Journal], 2016, no. 5 (353), pp. 44-60 (In Russian).

7. Zarubina L. V. Growth of under-log renewal of spruce in felling areas of blueberry birch forest. Izvestiya Sankt-Peterburgskoy lesotekhnicheskoy akademii [News of the Saint-Petersburg Forestry Academy], 2016, no. 216, pp. 58-68 (In Russian).

8. Shakhov A. G., Gryazkin A. V., Nguyen V.Z. Self-renewal of spruce in areas of forest crops. Mezhdunarodnyy nauchnyy zhurnal "Simvol nauki" [International scientific journal "Symbol of Science"], no. 4/2016. Available at: https://cyberleninka.ru/article/n/ samovozobnovlenie-eli-na-ploschadyah-lesnyhkultur (accessed 11.03.2021).

9. Torbik D. N. Izmeneniye ekologicheskikh faktorov $v$ svyazi s rubkami i ikh vliyaniye na formirovaniye nasazhdeniy [Changes in environmental factors in connection with logging and their influence on the formation of plantations]. Arkhangel'sk, Pomorskiy gosudarstvennyy universitet imeni M. V. Lomonosova Publ., 2010. 20 p.

10. Usoltsev V. A., Semyshev M. M. Produktsionnyye kharakteristiki s uchetom konkurentsii derev'yev $v$ iskusstvennykh i estestvennykh sosnyakakh: sravnitel'nyy analiz [Productive characteristics taking into account the competition of trees in artificial and natural pine forests: a comparative analysis]. Ekaterinburg, UrORAN Publ., 2007. 137p.

11. Sennov S. N. Results of an experimental study of competition in stands. Izvestiya SanktPeterburgskoy lesotekhnicheskoy akademii [St. Petersburg Forestry Engineering Academy], 1993. 172 p. (In Russian).

12. Kotsan V. V. The relationship between taxation indicators of trees in the circles of competition on the example of mossy pine forests of artificial origin. Trudy BGTU [Proceedings of BSTU], 2014, no. 1, Forestry, pp. 19-22 (In Russian).

13. Kotsan V. V Classification of trees based on spatial structure when assigned to thinning. Trudy $B G T U$ [Proceedings of BSTU], 2015, no. 1, Forestry, pp. 24-27 (In Russian).

14. Kotsan V. V. Assessment of the influence of spatial structure on taxation indicators of stands using a digital model of spatial distribution. Tezisy dokladov 76-y nouch.-tekhn. konf. professorskoprepodavatel'skogo sostava, nauchnykh sotrudnikov i aspirantov "Lesnoye khozyaystvo" [Abstracts of the 76th scientifie and technical. conf. faculty, researchers and graduate students "Forestry"]. Minsk, 2012. P. 13 (In Russian).

15. Sevko O. A. Assessment of the dependence of the current growth of the pine part of mixed pinebirch stands on their spatial structure. Trudy BGTU [Proceedings of BSTU], 2015, no. 1, Forestry, pp. 4145 (In Russian).

\section{Информация об авторе}

Севко Оксана Александровна - кандидат сельскохозяйственных наук, доцент, доцент кафедры лесоустройства. Белорусский государственный технологический университет (220006, г. Минск, ул. Свердлова, 13a, Республика Беларусь). E-mail: o.sevko@belstu.by

\section{Information about theauthor}

Sevko Oksana Aleksandrovna - PhD (Agriculture), Associate Professor, Assistant Professor, the Department of Forest Inventory. Belarusian State Technological University (13a, Sverdlova str., 220006, Minsk, Republic of Belarus). E-mail: o.sevko@belstu.by 